\title{
Pesquisa do vírus T-linfotrópico humano (HTLV) em amostras de secreção cérvico- vaginal de mulheres, em Belém, Pará, Brasil
}

Human T-lymphotropic virus (HTLV) research in cervical-vaginal discharge samples from women, in Belém, Pará, Brazil

Investigación del virus linfotrópico T humano (HTLV) en muestras de secreción cervical-vaginal de mujeres, en Belém, Pará, Brasil

Cássia Cristine Costa Pereira ORCID: https://orcid.org/0000-0002-3175-1742

Universidade Federal do Pará, Brasil

E-mail: cassiaccpereira@ hotmail.com

Debora Glenda de Lima La-Roque ORCID: https://orcid.org/0000-0001-9032-7485

Universidade de São Paulo, Brasil

E-mail: debora.laroque@gmail.com

Rosilma dos Santos Albuquerque ORCID: https://orcid.org/0000-0002-4978-0461

Faculdade Integrada Brasil-Amazônia, Brasil

E-mail: rose.rosilma@gmail.com

Ingrid Christiane Silva

ORCID: https://orcid.org/0000-0002-9753-6041 Universidade Federal do Pará, Brasil

E-mail: ingridchristiane22@gmail.com

Louise de Souza Canto Covre

ORCID: https://orcid.org/0000-0002-7510-6147

Universidade Federal do Pará, Brasil

E-mail: louisecanto12@yahoo.com.br

Akim Felipe Santos Nobre

ORCID: https://orcid.org/0000-0002-8501-9346 Universidade Federal do Pará, Brasil

E-mail: akimnobre@hotmail.com

Maria de Nazaré Lima dos Reis ORCID: https://orcid.org/0000-0002-9166-7630

Faculdade Integrada Brasil-Amazônia, Brasil

E-mail: marreiss.10@gmail.com

Izabela Mendonça de Assis

ORCID: https://orcid.org/0000-0002-9757-6799

Universidade Federal do Pará, Brasil

E-mail: izabela_stm@hotmail.com

Josiellem Damasceno de Souza

ORCID: https://orcid.org/ 0000-0002-5484-0553

Universidade Federal do Pará, Brasil

E-mail: josiellemd@gmail.com

Suellen Souza de Moraes

ORCID: https://orcid.org/0000-0002-0364-0623

Universidade Federal do Pará, Brasil

E-mail: suhsouzamoraes@gmail.com

Paula Fernanda Sant'Anna Lima Santos

ORCID: https://orcid.org/0000-0003-2501-0283

Universidade Federal do Pará, Brasil

E-mail: paulabiomed407@gmail.com

Lidia Bolivar Luz da Silva

ORCID: https://orcid.org/0000-0003-1749-8725

Universidade Federal do Pará, Brasil

E-mail: bolivarlidia@gmail.com

Danilo de Souza Almeida

ORCID: https://orcid.org/0000-0003-4528-9269

Universidade Federal do Pará, Brasil

E-mail: almeida.danilo.ufpa@gmail.com 


\author{
Maísa Silva de Sousa \\ ORCID: https://orcid.org/0000-0001-9944-7838 \\ Universidade Federal do Pará, Brasil \\ E-mail: maisasousa@ufpa.br
}

\begin{abstract}
Resumo
O Pará está entre os estados brasileiros com as mais elevadas taxas de prevalências da infecção pelo vírus Tlinfotrópico humano (HTLV) nas populações onde este vírus já foi investigado. A infecção por HTLV geralmente apresenta prevalência mais elevada em mulheres com mais de 40 anos e com relacionamento estável. Além disso, as mulheres são mais susceptíveis à aquisição do vírus por via sexual do que os homens. Neste contexto, este estudo teve como objetivo detectar o genoma do provírus de HTLV em secreção cérvico-vaginal, com posterior confirmação em amostras de sangue, visando assim, propor uma nova metodologia de rastreamento desta infecção. Foram investigadas 400 mulheres de novembro de 2015 a dezembro de 2019, em Belém, Pará, Brasil. A coleta de secreção cérvicovaginal se deu durante a realização do exame de Papanicolaou, e a de sangue periférico, durante contato posterior. O DNA das amostras foi extraído e realizada a análise molecular por Nested-PCR, seguida de digestão enzimática por Taq I, para pesquisa da infecção pelos tipos HTLV-1 e HTLV-2. Cinco (1,25\%) das 400 mulheres tiveram resultado positivo para HTLV em secreção, sendo três para HTLV-1 e duas para HTLV-2. Por dificuldade de contato, só foi possível a confirmação da infecção no sangue em uma destas cinco mulheres. Nossos achados sugerem ser possível utilizar amostras de secreção cérvico-vaginal como mais uma forma de rastreamento da infecção por HTLV em mulheres.
\end{abstract}

Palavras-chave: Saúde da mulher; Doenças virais sexualmente transmissíveis; Infecções por retrovírus; Deltaretrovírus.

\begin{abstract}
Pará is among the Brazilian states with the highest prevalence rates of infection by the human T-lymphotropic virus (HTLV) in populations where this virus has already been investigated. HTLV infection generally has a higher prevalence in women over 40 and in a stable relationship. Furthermore, women are more susceptible to acquiring the virus through sexual intercourse. In this context, this study aimed to detect the HTLV provirus in vaginal-cervical discharge, with subsequent confirmation of the infection in blood samples, thus aiming to propose a new methodology for tracking the infection. A total of 400 women were investigated from November 2015 to December 2019, in Belém, Pará, Brazil. The vaginal-cervical discharge was collected during the Papanicolaou test (Pap test), and the peripheral blood, during posterior contact. After collection, the DNA of the samples was extracted and molecular analysis by Nested-PCR was performed, followed by a enzymatic digestion by Taq I, for detection of the infection by HTLV-1 or HTLV-2. Five (1.25\%) of the 400 women tested positive for HTLV in vaginal-cervical discharge, three of them being HTLV-1 and two HTLV-2. Due to inaccessibility, it was only possible to confirm the blood infection in one of these five women. Our findings suggest that it is possible to use cervical-vaginal discharge samples as an alternative screening test for HTLV infection in women.
\end{abstract}

Keywords: Women's health; Sexually transmitted viral diseases; Retrovirus infections; Deltaretrovirus.

\title{
Resumen
}

Pará se encuentra entre los estados brasileños con mayores tasas de prevalencia de infección por el virus linfotrópico T humano (HTLV) en poblaciones donde este virus ya ha sido investigado. La prevalencia de la infección por HTLV es generalmente mayor en mujeres mayores de 40 años y mujeres casadas. Además de esto, las mujeres son más susceptibles a contraer el virus a través de relaciones sexuales. En este contexto, este estudio tuvo como objetivo detectar el genoma del provirus HTLV en la secreción cérvico-vaginal, con posterior confirmación de la infección en muestras de sangre, con el objetivo de proponer una nueva metodología para el seguimiento de esta infección. Se investigaron 400 mujeres desde noviembre de 2015 hasta diciembre de 2019 en Belém, Pará, Brasil. La recolección de muestras de secreción cervical-vaginal ocurrió durante la realización del Prueba de Papanicolaou (Pap), y la sangre periférica, durante el contacto posterior. Se extrajo el DNA de las muestras y se realizó análisis molecular por PCR anidada, seguido de digestión enzimática por Taq I, para confirmar la infección por los tipos HTLV-1 o HTLV-2. Cinco $(1,25 \%)$ de las 400 mujeres dieron positivo por secreción, tres de HTLV-1 y dos de HTLV-2. Debido a la dificultad de contacto, solo fue posible confirmar la infección sanguínea en una de estas cinco mujeres. Nuestros hallazgos sugieren que es posible utilizar muestras de secreción cervical-vaginal como otra forma de detección de la infección por HTLV en mujeres.

Palabras clave: La salud de la mujer; Enfermedades virales de transmisión sexual; Infecciones por retrovirus; Deltaretrovirus. 


\section{Introdução}

O Vírus T-linfotrópico Humano 1 (HTLV-1) foi descrito na década de 1980 por um grupo estadunidense e identificado como agente etiológico da Leucemia/Linfoma de Células T do Adulto (ATL), doença previamente descrita no Japão (Poiesz et al., 1980; Popovic et al., 1982). Dentre os quatro tipos virais já descritos (HTLV-1, HTLV-2, HTLV-3, HTLV-4), o HTLV-1 é o mais associado ao desenvolvimento de patologias. Além da ATL, a infecção pelo HTLV-1 também está relacionada à Paraparesia espástica tropical/Mielopatia associada ao HTLV-1 (TSP/HAM), uma doença neurodegenerativa, e à outras doenças associadas, tais como estrongiloidíase, artrites, dermatites e uveítes. Por sua vez, existem estudos relacionando a infecção pelo HTLV-2 a doenças neurológicas e hematológicas (Futsch et al., 2017). Dentre as características da infecção pelo HTLV estão o elevado número de portadores assintomáticos, a soroconversão tardia e a distribuição heterogênea no mundo (Schierhout et al., 2019).

Ambos, o HTLV-1 e o HTLV-2, encontram-se distribuídos globalmente. Estima-se que de 5 a 10 milhões de pessoas estejam infectadas em todo o planeta (Gessain \& Cassar, 2012), com endemicidade em partes da Ásia (prevalentemente no sudoeste do Japão), ilhas do Caribe, América Central e do Sul, África Central, ilhas da Melanésia na Bacia do Pacífico e em população aborígene da Austrália (Gessain \& Cassar, 2012). Acredita-se que o Brasil seja o país com o maior número de portadores do HTLV, com cerca de 2,5 milhões de portadores do vírus (Carneiro-Proietti et al., 2002). A infecção está presente em todos os estados do Brasil com diferentes prevalências, sendo o Pará um dos que apresenta maior prevalência em diversas populações já investigadas, como em ribeirinhos (Ferreira et al., 2010), doadores de sangue (Santos et al., 2009), familiares de portadores (Costa et al., 2013), transeuntes da cidade de Belém (Silva et al., 2018), dentre outros.

Em estudos realizados na capital paraense, foi encontrada prevalência elevada da infecção em mulheres com idade superior a 40 anos, com relacionamento estável, associada à forma como a infecção pelo vírus é perpetuada em áreas endêmicas (Costa et al., 2013; Glória et al., 2015). O HTLV pode ser transmitido pelas vias vertical, parenteral ou sexual. A via vertical pode ocorrer via transplacentária, durante o parto (Tezuka et al., 2020) e, principalmente, da mãe para o lactente (Moriuchi et al., 2013); a via parenteral ocorre por transfusão sanguínea e/ou compartilhamento de agulhas e seringas contaminadas (Satake et al., 2016), enquanto a transmissão sexual pode ocorrer por relacionamento prolongado sem uso de preservativo, sendo mais eficaz do homem para a mulher (Paiva et al., 2017; Braço et al., 2019). Em áreas endêmicas, a transmissão do HTLV ocorre principalmente pelo contato sexual desprotegido e/ou amamentação (Ishak et al., 2020).

O genoma proviral do HTLV já foi detectado em sêmen e em secreção cérvico-vaginal de indivíduos sabidamente infectados pelo HTLV, onde, geralmente, encontra-se maior concentração de linfócitos infectados no sêmen (Pique \& Jones, 2012; WHO, 2021), fator que pode estar associado à maior eficácia de transmissão via sexual no sentido do homem para a mulher (Kajiyama et al., 1986). Outros fatores também aumentam a susceptibilidade das mulheres em adquirir o vírus por via sexual, dentre eles: a pré-existência de Infecções Sexualmente Transmissíveis (IST), múltiplos parceiros sexuais, ausência de parceiro sexual fixo e a não utilização de preservativos (Mayer \& Venkatesh, 2011; Mylonas et al., 2010).

A triagem da infecção ocorre pela busca de anticorpos anti-HTLV no plasma ou soro. Testes confirmatórios para detecção e para a diferenciação do tipo viral devem ser realizados quando o teste de triagem for positivo. Dentre estes, destacam-se o Western blot e imunoensaio em linha (INNOLIA), que identificam anticorpos contra antígenos específicos do HTLV-1 e do HTLV-2 e a reação em cadeia da polimerase (PCR), que se baseia na amplificação do genoma proviral (Rosadas et al., 2021).

O exame de Papanicolaou é o método de rastreamento do câncer do colo do útero (CCU) realizado no Brasil, o qual deve ser oferecido às mulheres com colo do útero, que apresentam vida sexual ativa, com prioridade para aquelas com idade entre 25 e 64 anos. Este exame, além da detecção de lesões precursoras do CCU, visa também o diagnóstico de inflamações e infecções vaginais, como algumas IST (Inca, 2021). Como as mulheres tendem a ser mais suscetíveis à aquisição do HTLV por 
via sexual, além da característica de soroconversão tardia, observada em portadores desta infecção, é importante buscar alternativas que possam detectar o vírus precocemente em possíveis processos de transmissões sexuais da infecção. Sendo assim, este trabalho teve como objetivo pesquisar o genoma do provírus do HTLV em amostras de secreção cérvico-vaginal, com posterior confirmação e genotipagem da infecção no sangue de mulheres de Belém, Pará, Brasil.

\section{Metodologia}

\subsection{Tipo e população de estudo}

Este é um estudo de pesquisa laboratorial, de natureza quantitativa observacional transversal (Bonita et al., 2010). Foram investigadas mulheres com idade superior a 18 anos que realizaram o exame de Papanicolaou em ações de extensão universitária de uma universidade pública federal, entre novembro de 2015 e dezembro de 2019, em Belém, Pará, Brasil.

\subsection{Coleta das amostras e dados epidemiológicos}

O Termo de Consentimento Livre e Esclarecido foi assinado pela participante da pesquisa previamente à coleta de dados e de amostra. O levantamento de fatores socioepidemiológicos foi realizado com o preenchimento de formulário próprio do projeto.

A coleta de amostra cérvico-vaginal ocorreu seguindo as orientações do Ministério da Saúde (Inca, 2021). Para a análise molecular, o material coletado com a escova endocervical foi armazenado em microtubos contendo $300 \mu \mathrm{L}$ de 1x TrisEDTA (TE), estocados a $-20^{\circ} \mathrm{C}$ até a etapa de extração de ácidos nucléicos.

Nos casos em que o genoma viral foi detectado em secreção cérvico-vaginal, a participante da pesquisa foi convidada a retornar ao laboratório para a coleta de amostra sanguínea, que consistiu na coleta de $5 \mathrm{~mL}$ de sangue periférico em tubo com anticoagulante (EDTA) para a pesquisa do DNA proviral do HTLV.

\subsection{Extração do DNA e reação de $\beta$-globina humana}

A extração do DNA das amostras de secreção cérvico-vaginal e sanguínea ocorreu por meio do kit illustra ${ }^{\mathrm{TM}}$ blood genomicPrep Mini Spin Kit (GE Healthcare), seguindo o protocolo estabelecido pelo fabricante.

Após a extração do DNA, todas as amostras foram submetidas à reação de PCR da $\beta$-globina humana para avaliar a integridade e adequabilidade do material extraído. A reação é baseada na amplificação de uma região específica do gene da $\beta$ globina humana, resultando em um fragmento de 268 pares de base (pb), de acordo com o protocolo estabelecido por Bell e colaboradores, em 1993 (Bell et al., 1993). As amostras negativas nesta reação foram excluídas do estudo.

\subsection{Pesquisa do DNA proviral do HTLV e genotipagem}

Para a pesquisa do DNA proviral do HTLV, parte da região $p X$ do genoma proviral foi amplificado por Nested-PCR. A primeira etapa da Nested-PCR foi feita em uma solução contendo 3,5 $\mu \mathrm{L}$ de Master Mix, $1,0 \mu \mathrm{L}$ de $\mathrm{H}_{2} \mathrm{O}, 0,25 \mu \mathrm{L}$ (concentração a 10 pmol) dos iniciadores: HTLVExt Forward 5'- TTC CCA GGG TTT GGA CGA AG-3' (7219-7238, forward) e HTLVExt Reverso 5'-GGG TAA GGA CCT TGA GGG TC-3' (7483-7464, reverso) e 2,0 $\mu$ L de DNA genômico previamente extraído. A solução foi submetida à reação em termociclador, seguindo a ciclagem descrita por Silva et al., 2018; tendo como resultado da amplificação um fragmento de $259 \mathrm{pb}$.

Para a segunda reação da Nested-PCR, foram utilizados 6,0 $\mu \mathrm{L}$ de Master Mix, 0,25 $\mu \mathrm{L}$ (concentração a 10 pmol) dos iniciadores, HTLVInt Forward 5'-CGG ATA CCC AGT CTA CGT GTT-3' (7248-7268, forward) e HTLVInt Reverso 5'-GAG CCG ATA ACG CGT CCA TCG-3' (7406-7386, reverso), 5,2 $\mu \mathrm{L}$ de $\mathrm{H}_{2} \mathrm{O}$ e $0,3 \mu \mathrm{L}$ do produto da PCR realizada previamente. 
A solução foi submetida a um novo ciclo de reação em termociclador, seguindo ciclagem descrita por Silva et al., 2018; obtendo ao final da amplificação um fragmento de 159 pb.

Os produtos da amplificação foram visualizados, após eletroforese (100 V/60 minutos) em tampão 1x TAE (50x TAE- $\mathrm{C}_{4} \mathrm{H}_{11} \mathrm{NO}_{3}$ 1,6 M, $\mathrm{C}_{2} \mathrm{H}_{3} \mathrm{NaO}_{2}$ 0,8 M e EDTA-Na $40 \mathrm{mM} / 1000 \mathrm{~mL}$ de $\mathrm{H}_{2} \mathrm{O}$ deionizada) e gel de agarose a $2 \%$, corado com Brometo de etídio $\left(\mathrm{C}_{21} \mathrm{H}_{20} \mathrm{BrN}_{3}\right)$, mediante a utilização de transiluminador ultravioleta.

Após a identificação de amostras positivas na Nested-PCR foi feita a reação de Polimorfismo de Comprimento do Fragmentos de Restrição (RFLP) do produto amplificado, para a diferenciação dos tipos virais (HTLV-1 ou HTLV-2),. Na reação de RFLP do produto da Nested-PCR do gene $p X$, o sítio de restrição da enzima Taq I (T/CGA) gera 2 fragmentos (138 pb e 21 pb) no HTLV-1 e 3 fragmentos ( 85 pb, 53 pb e 21 pb) no HTLV-2, o que pode ser visualizado após a eletroforese em gel de agarose a $3 \%$ (Silva et al., 2018).

Durante todas as etapas da PCR foram utilizados controles positivos (amostras sabidamente positivas para HTLV-1 e HTLV-2) e negativos (amostra negativa) para controle interno da reação. As etapas de amplificação do genoma proviral e genotipagem seguiram os mesmos protocolos em amostras de secreção cérvico-vaginal e de sangue. Todas as etapas de amplificação do genoma foram repetidas duas ou mais vezes, a fim de confirmar os resultados obtidos.

\subsection{Comitê de ética}

Este estudo fez parte de um projeto de pesquisa intitulado "Pesquisando infecções e doenças infecciosas na extensão universitária”, aprovado pelo Comitê de Ética em Pesquisa (CEP) da Universidade Federal do Pará (UFPA), com o número do parecer CEP: 1.218.417, em 08/09/2015.

\subsection{Armazenamento de dados e análises estatísticas}

Os dados coletados durante este estudo foram inseridos em planilhas Microsoft Office Excel, onde foram realizadas as análises descritivas de média e desvio padrão. Para a confecção de gráficos e análises inferenciais foi utilizado o software GraphPad Prism, versão 8.0.2, e o software BioEstat, versão 5.3, respectivamente. Os dados de idade foram avaliados quanto à distribuição normal (testes D'Agostino-Pearson e Shapiro-Wilk). As tabelas de contingência relativas ao número de parceiros sexuais, à presença ou ausência de parceiro fixo e à idade foram analisadas pelo teste exato de Fisher, enquanto a tabela relativa ao uso de preservativo foi avaliada pelo teste G. O p-valor bilateral $\leq 0,05$ foi considerado estatisticamente significativo.

\section{Resultados}

Ao total, 400 mulheres tiveram amostra de secreção cérvico-vaginal investigada, dentre as quais cinco $(1,25 \%)$ apresentaram o genoma proviral do HTLV de forma detectável. A idade das participantes variou entre 18 e 80 anos, com idade média de 35 anos. A idade das cinco mulheres (com genoma proviral de HTLV detectável em secreção cérvico-vaginal) variou de 35 a 60 anos, com média de 47 anos ( \pm 9 anos) (Figura 1). Destas, quatro (80,0\%) apresentaram idade superior a 40 anos. 
Figura 1. Boxplot da média de idade das mulheres investigadas e com genoma proviral de HTLV detectável na secreçãocérvico-vaginal, entre 2015 e 2019, em Belém, Pará, Brasil.

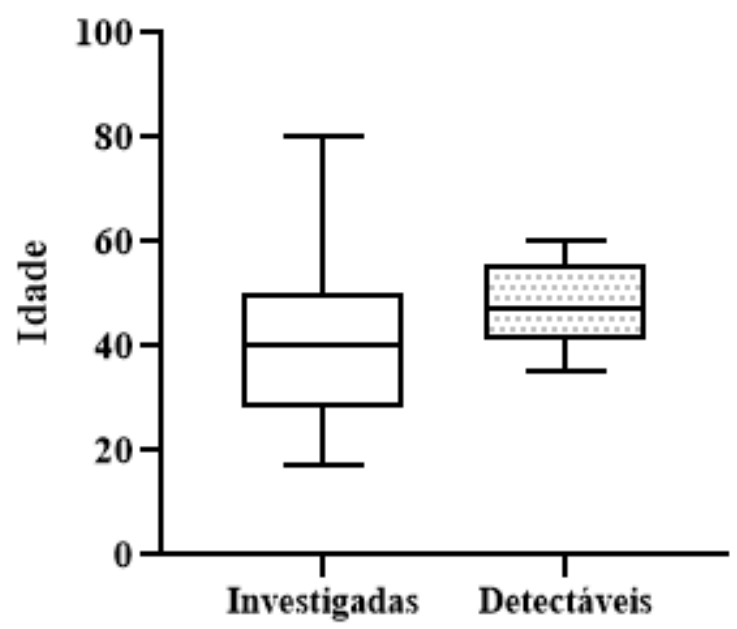

Fonte: Autores (2021).

Das mulheres investigadas, $213(53,25 \%)$ relataram ter tido de 1 a 5 parceiros sexuais em toda a vida, $203(50,75 \%)$ relataram ter parceiro sexual fixo e 135 (33,75\%) declararam utilizar preservativo em todas as relações sexuais. Na Tabela 1, é possível observar que a presença do DNA proviral do HTLV se destacou $(3,82 \%)$ na secreção cérvico-vaginal de mulheres que nunca fizeram uso de preservativo durante a relação sexual $(\mathrm{p}=0,0108)$. A Tabela 1 apresenta o perfil epidemiológico das participantes da pesquisa e a frequência de casos com detecção proviral do HTLV na secreção cérvico-vaginal, quanto aos possíveis fatores de risco para aquisição do HTLV por via sexual. 
Tabela 1. Perfil epidemiológico e frequência de casos com detecção proviral na secreção cérvico-vaginal, de acordo com os fatores sexuais considerados de risco para aquisição da infecção por HTLV, nas mulheres investigadas entre 2015 e 2019 , em Belém, Pará, Brasil.

\begin{tabular}{|c|c|c|c|c|c|}
\hline \multirow{2}{*}{ Variável investigada } & \multicolumn{2}{|c|}{ Investigadas } & \multicolumn{2}{|c|}{ Detectáveis } & \multirow{2}{*}{ p-valor } \\
\hline & $\mathbf{n}$ & $\%$ & $\mathbf{n}$ & $\%$ & \\
\hline Número de parceiros sexuais & & & & & 0,0809 \\
\hline 1 a 5 & 218 & $54,50 \%$ & 5 & $2,29 \%$ & \\
\hline$>5$ & 152 & $38,00 \%$ & 0 & $0,00 \%$ & \\
\hline Não informado & 30 & $7,50 \%$ & 0 & $0,00 \%$ & \\
\hline Parceiro sexual fixo & & & & & $>0,9999$ \\
\hline $\operatorname{Sim}$ & 203 & $50,75 \%$ & 3 & $1,48 \%$ & \\
\hline Não & 145 & $36,25 \%$ & 2 & $1,38 \%$ & \\
\hline Não informado & 52 & $13,00 \%$ & 0 & $0,00 \%$ & \\
\hline Uso de preservativo & & & & & $0,0108^{*}$ \\
\hline Sempre & 135 & $33,75 \%$ & 0 & $0,00 \%$ & \\
\hline Nunca & 131 & $32,75 \%$ & 5 & $3,82 \%$ & \\
\hline Às vezes & 96 & $24,00 \%$ & 0 & $0,00 \%$ & \\
\hline Não informado & 38 & $9,50 \%$ & 0 & $0,00 \%$ & \\
\hline Idade & & & & & 0,3753 \\
\hline$<40$ anos & 172 & $43,00 \%$ & 1 & $0,58 \%$ & \\
\hline$\geq 40$ anos & 189 & $47,25 \%$ & 4 & $2,12 \%$ & \\
\hline Não informado & 39 & $9,75 \%$ & 0 & $0,00 \%$ & \\
\hline
\end{tabular}

* Valor significativo para teste G. Fonte: Autores (2021).

Das cinco (1,25\%) amostras de secreção cérvico-vaginal com DNA proviral detectável, três $(0,75 \%)$ foram identificadas com HTLV-1 e duas $(0,5 \%)$ com HTLV-2. Na Figura 2 é possível visualizar na fotodocumentação dos géis de agarose a $2 \%$, após eletroforese, o fragmento de 159 pb gerado por Nested-PCR das cinco amostras de secreção cérvicovaginal onde foi detectado o genoma do provírus. A Figura 3 apresenta a fotodocumentação do gel de agarose a 3\%, com o resultado da reação de RFLP do produto da Nested-PCR de duas amostras, ambas com resultado positivo para o HTLV-2. 
Figura 2. Fotodocumentação dos géis de agarose a 2\%, com os produtos da Nested-PCR das amostras de secreção cérvicovaginal positivas para HTLV, corados com brometo de etídio. Amostras (P01, P02, P03, P04 e P05). Fragmentos amplificados de 159 pb. CP: controle positivo. CN: controle negativo. L: Ladder de 100 pb.

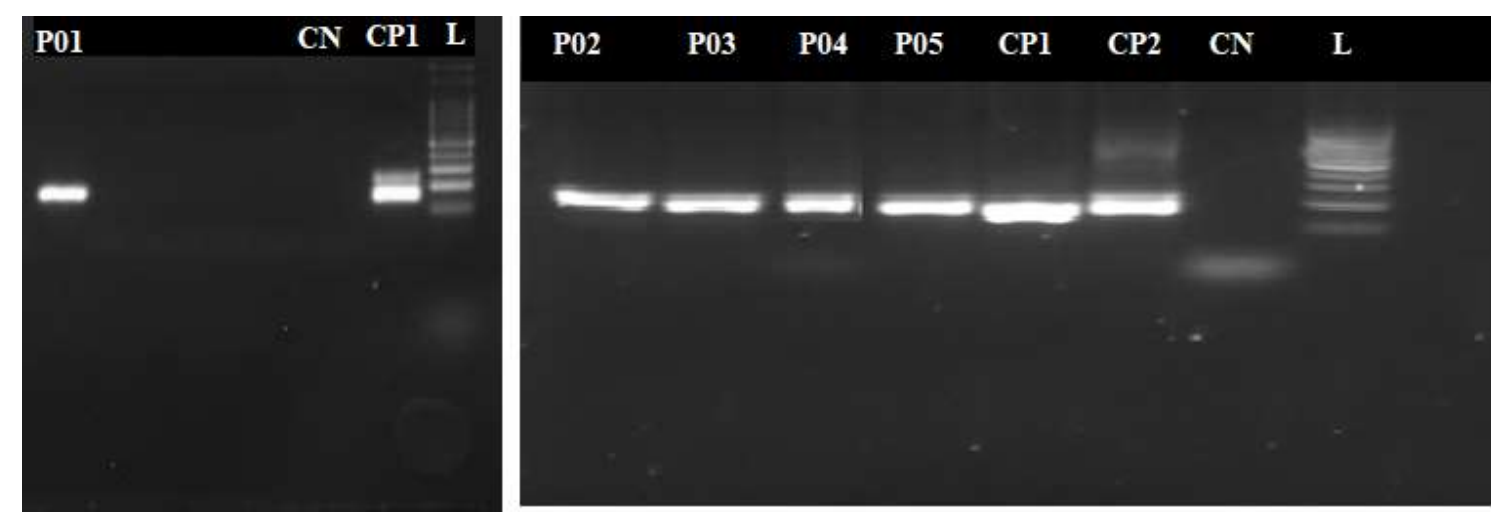

Fonte: Autores (2020).

Figura 3. Fotodocumentação de gel de agarose a 3\%, com os fragmentos específicos de HTLV-2 gerados após a reação de RFLP, corado com brometo de etídio. Amostras (P04 e P05) positivas para HTLV-2. CN: controle negativo. L: Ladder 100pb.

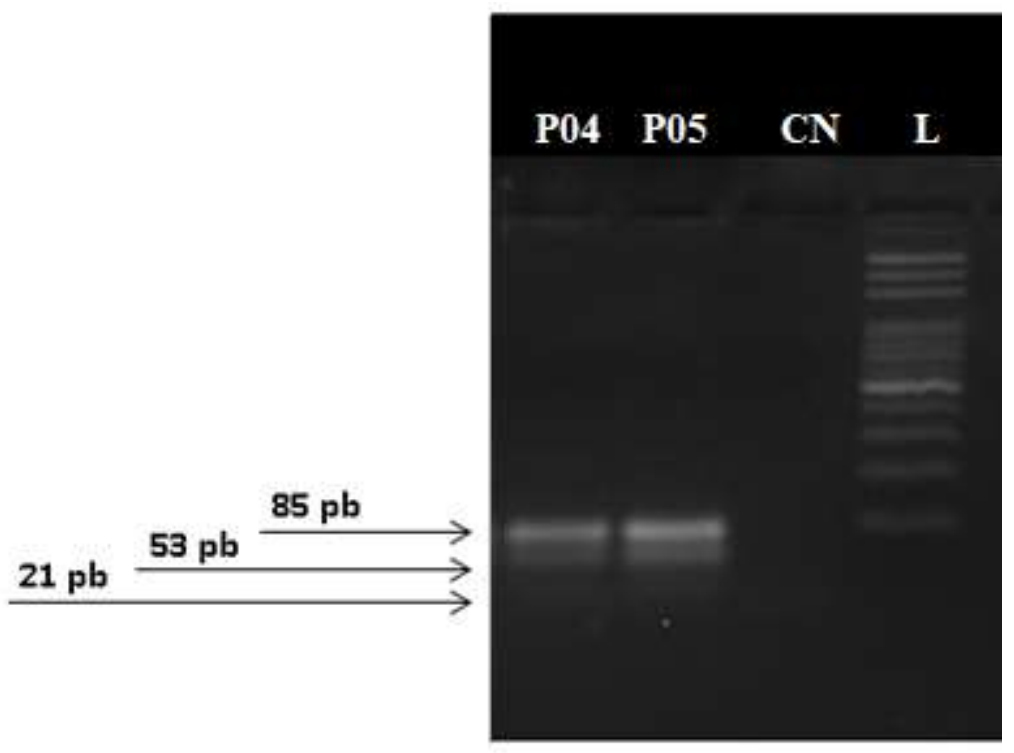

Fonte: Autores (2020).

Quanto ao perfil epidemiológico das mulheres com resultado positivo para HTLV-1 em secreção cérvico-vaginal:

P01 - 60 anos, declarou ter parceiro sexual fixo e ter tido dois ao longo de toda a vida, não utilização de preservativo em todas as relações sexuais. Por impossibilidade de contato não foi possível a coleta do sangue da participante;

P02 - 35 anos, com parceiro sexual fixo e dois em toda a vida, não utilização de preservativo em todas as relações sexuais. Por impossibilidade de contato não foi possível a coleta do sangue da participante;

P03 - 51 anos, não apresentava parceiro sexual fixo, mas declarou ter tido relação estável (cerca de 6 anos) até pouco tempo da data da coleta. Declarou ter tido um único parceiro sexual em toda a vida e não utilizar preservativo nas relações sexuais. Por impossibilidade de contato não foi possível a coleta do sangue da participante;

Quanto ao perfil epidemiológico das mulheres com resultado positivo para HTLV-2 em secreção cérvico-vaginal: 
P04 - 47 anos, sem parceiro sexual fixo, com dois parceiros sexuais em toda a vida. Não utiliza de preservativo nas relações sexuais. Foi feita a coleta de sangue periférico, onde foram aplicados os mesmos protocolos para a detecção do genoma viral em secreção vaginal, e confirmada a infecção por HTLV-2.

P05 - 47 anos, declarou ter parceiro sexual fixo e apenas este em toda a vida. Não utilização de preservativo durante as relações sexuais. Por impossibilidade de contato não foi possível a coleta do sangue da participante;

Os fatores socioepidemiológicos das cinco mulheres com resultado positivo para HTLV em amostras de secreção cérvico-vaginal estão apresentados na Tabela 2.

Tabela 2. Fatores epidemiológicos das mulheres com resultado positivo para HTLV em secreção cérvico-vaginal, investigadas entre 2015 e 2019, em Belém, Pará, Brasil.

\begin{tabular}{ccccccc}
\hline Paciente & Idade & $\begin{array}{c}\text { Parceiro } \\
\text { fixo }\end{array}$ & $\begin{array}{c}\text { Parceiros } \\
\text { na vida }\end{array}$ & $\begin{array}{c}\text { Uso de } \\
\text { preservativo }\end{array}$ & $\begin{array}{c}\text { PCR } \\
\text { secreção }\end{array}$ & $\begin{array}{c}\text { PCR } \\
\text { sangue }\end{array}$ \\
\hline $\mathbf{P 0 1}$ & 60 & Sim & 2 & Não & HTLV-1 & NR* \\
$\mathbf{P 0 2}$ & 35 & Sim & 2 & Não & HTLV-1 & NR* \\
$\mathbf{P 0 3}$ & 51 & Não & 1 & Não & HTLV-1 & NR* \\
$\mathbf{P 0 4}$ & 47 & Não & 2 & Não & HTLV-2 & HTLV-2 \\
$\mathbf{P 0 5}$ & 47 & Sim & 1 & Não & HTLV-2 & NR* \\
\hline
\end{tabular}

*NR: Não realizado. Fonte: Autores (2020).

\section{Discussão}

A infecção pelo HTLV é conhecida por se disseminar de forma silenciosa entre pessoas da mesma família, principalmente pelas vias vertical e sexual (Pereira et al., 2019). Em mulheres, observa-se uma prevalência elevada da infecção com o aumento da idade, quando a transmissão via sexual é mais provável de acontecer (Schierhout et al., 2019). Sabe-se que a transmissão sexual é cerca de seis vezes mais provável de acontecer no sentido do homem para mulher do que no sentido inverso (Costa et al., 2013), fato este explicado por aspectos biológicos como a maior concentração de linfócitos infectados no sêmen (WHO, 2021). Ademais, estudos anteriores relataram que, na região amazônica, a principal via de transmissão da infecção por HTLV é a sexual (Costa et al., 2013, Ishak et al., 2020). Neste sentido, a pesquisa por métodos moleculares em amostras de secreção cérvico-vaginal se mostra relevante, por ser uma alternativa de elevada sensibilidade e especificidade para o rastreamento da infecção neste público mais vulnerável.

Das mulheres com o DNA proviral de HTLV em secreção cérvico-vaginal, observou-se que quatro apresentaram idade superior a 40 anos e uma com 35 anos. Este achado corrobora o que já está descrito na literatura sobre a prevalência da infecção pelo HTLV aumentar significativamente em mulheres de 30, 40 anos ou mais (Glória et al., 2015; Silva et al., 2018). Este fato pode estar relacionado a uma maior exposição da mulher ao vírus pelo contato sexual e/ou à forma lenta como a infecção se dissemina pelo organismo, por meio do contato célula-a-célula, levando a um grande período de latência (Bangham, 2018). Ademais, nenhuma destas mulheres relatou o uso do preservativo durante as relações sexuais até o momento do estudo, fator considerado de risco para a aquisição da infecção por HTLV e demais IST (Mylonas et al., 2010; Mome et al., 2018; Barbosa et al., 2020). 
A possibilidade de detecção do genoma proviral de HTLV em secreção cérvico-vaginal corrobora outros estudos já realizados que investigaram a presença do HTLV-1 e do HIV-1 em secreção cérvico-vaginal (Bélec et al., 1996; Zunt et al., 2002; Johnson \& Lewis, 2008). Segundo Zunt e colaboradores (2002), a presença do genoma proviral do HTLV-1 em secreção cérvico-vaginal está relacionada a quadros clínicos de cervicite. Ademais, Johnson e Lewis (2008) mostraram que, em infecções que provocam um recrutamento de linfócitos ao trato genital, a secreção do HIV-1 mostra-se aumentada. Neste sentido, embora não tenha sido possível a coleta de amostra sanguínea para a confirmação da infecção de todas as mulheres que obtiveram resultado positivo para HTLV em secreção cérvico-vaginal, nossos achados sugerem que um processo de transmissão sexual pode estar em andamento ou ainda, uma infecção não descoberta ou confirmada por parte da mulher. Estudos complementares serão necessários para a melhor a melhor compreensão da infecção por HTLV em mulheres que apresentem o genoma proviral na secreção cérvico-vaginal.

A frequência $(0,75 \%)$ do genoma proviral de HTLV-1 em secreção cérvico-vaginal encontrada nas mulheres deste estudo não parece diferir das prevalências observadas em mulheres grávidas do Maranhão $(0,2 \%)$ (Souza et al., 2012) e da Bahia (1,05\%) (Mello et al., 2014). Mais estudos são necessários para confirmar se os achados deste estudo representam a prevalência da infecção por HTLV-1 em mulheres que realizam o exame de Papanicolaou.

A detecção do HTLV-2 em amostras de secreção cérvico-vaginal ocorreu de forma pioneira neste estudo. Tendo em vista a paciente P04 que obteve o resultado positivo primeiramente em secreção cérvico-vaginal, com posterior confirmação em sangue, para HTLV-2, é possível inferir que a busca em secreção cérvico-vaginal funcionou como um método de rastreamento precoce da infecção. Para confirmar a via de transmissão - horizontal ou vertical, seria necessário investigar também o parceiro sexual (que a paciente informou não ter no momento da coleta) e a mãe da paciente, visto que existe a possibilidade de contaminação por aleitamento materno durante a infância.

É importante ressaltar que a região amazônica é considerada endêmica para a infecção pelo HTLV. Estudos indicam que a Amazônia brasileira possui uma das mais elevadas prevalências para HTLV-2 no mundo (Roucoux \& Murphy, 2004; Braço et al., 2019). Diversos estudos já encontraram prevalências significativas de HTLV-2 em populações indígenas (foi encontrado em 17 das 26 comunidades indígenas investigadas) (Black et al., 1994; Ishak et al., 2003; Roucoux \& Murphy, 2004; Braço et al., 2019), assim como na própria cidade de Belém (PA), onde duas (16,7\%) de 12 pessoas que doaram sangue e que apresentaram sorologia reagente durante a triagem em banco de sangue, foram confirmadas com infecção por HTLV-2 (Ishak et al., 1998).

\section{Conclusão}

Neste estudo foi possível detectar o genoma proviral do HTLV-2 em secreção cérvico-vaginal de uma mulher que confirmou a infecção também no sangue. Este e os demais achados sugerem que a detecção do genoma proviral do HTLV em secreção cérvico-vaginal pode ser usada como método de rastreamento precoce desta infecção viral. A detecção do genoma proviral do HTLV em secreção cérvico-vaginal pode representar um processo de transmissão sexual em andamento ou, ainda, que já exista uma infecção viral sistêmica, desconhecida por parte da mulher. Para confirmar esta hipótese serão necessários mais estudos.

Para esses estudos futuros, recomenda-se a coleta simultânea, de secreção cérvico-vaginal e de sangue, para confirmar a infecção em todas as mulheres que apresentarem o genoma proviral do HTLV na secreção. Além disso, é importante investigar o parceiro sexual e a mãe das mulheres infectadas, para investigar a origem da infecção.

\section{Referências}

Bangham, C. R. M. (2018). Human T Cell Leukemia Virus Type 1: Persistence and Pathogenesis. Annual review of Immunology. 36:25-53. 
Barbosa, M. M. et al. (2020). Conhecimento de estudantes adolescentes sobre Infecções Sexualmente Transmissíveis. Research, Society and Development, 9(9).

Bélec, L. et al. (1996). Cervicovaginal synthesis of IgG antibodies to the immunodominant 175-199 domain of the surface glycoprotein gp46 of human T-cell leukemia virus type I. Journal of medical virology, 50(1):42-9.

Bell, D. A., et al. (1993). Genetic risk and carcinogen exposure: a common inherited defect of the carcinogen-metabolism gene glutathione S-transferase M1 (GSTM1) that increases susceptibility to bladder cancer. Journal of the National Cancer Institute, 21;85(14):1159-64.

Black, F. L., et al. (1994). Endemic transmission of HTLV type II among Kayapo Indians of Brazil. AIDS Research and Human Retroviruses, 10(9):1165-71.

Bonita, R., et al. (2010). Epidemiologia básica (2a ed.). Santos editora.

Braço, I. L. J., et al. (2019). High prevalence of human T-lymphotropic virus 2 (HTLV-2) infection in villages of the Xikrin tribe (Kayapo), Brazilian Amazon region. BMC Infectious Diseases. 19 (1):459.

Carneiro-Proietti, A. B. F., et al. (2002). Infecção e doença pelos vírus linfotrópicos humanos de células T (HTLV-I/II) no Brasil. Revista da Sociedade Brasileira de Medicina Tropical, 35:499-508.

Catalan-Soares, B., et al. (2005). Heterogeneous geographic distribution of human T-cell lymphotropic viruses I and II (HTLV-I/II): serological screening prevalence rates in blood donors from large urban areas in Brazil. Cadernos de Saúde Pública, 21(3), 926-931.

Coelho, J., et al. (2018). Importância das ações de extensão universitária na prevenção de infecções e doenças associadas ao vírus linfotrópico-T humano. Revista Pan-Amazônica de Saúde, 9(1): 25-31.

Costa, C., et al. (2013). Familial transmission of human T-cell lymphotrophic virus: silent dissemination of an emerging but neglected infection. PLoS Neglected Tropical Diseases, 7(6).

Ferreira, L. et al. (2010). A Soroprevalência do vírus linfotrópico de células T humanas em comunidades ribeirinhas da região nordeste do Estado do Pará, Brasil. Revista Pan-Amazônica de Saúde, 20, 1(3):103-108.

Futsch, N., et al. (2017). HTLV-1, the Other Pathogenic Yet Neglected Human Retrovirus: From Transmission to Therapeutic Treatment. Viruses. 10(1):1.

Gallo, R., et al. (1982). HTLV: the virus of adult T-cell leukaemia in Japan and elsewhere. The Lancet, 20;1(8273):683.

Gessain, A., \& Cassar O. (2012). Epidemiological aspects and world distribution of HTLV-1 infection. Frontiers in Microbiology, 3(388): 1-23.

Glória, L. M., et al. (2015). Perfil clínicoepidemiológico de pacientes infectados pelo HTLV-1 em Belém/Pará. Cadernos de Saúde Coletiva, 23 (2): 157-62.

Inca. (2021). Ações de controle do câncer do colo do útero. https://www.inca.gov.br/controle-do-cancer-do-colo-do-utero/acoes-de-controle/deteccao-precoce.

Ishak, R., et al. (1998). Detection of HTLV-IIa in blood donors in an urban area of the Amazon Region of Brazil (Belém, PA). Revista da Sociedade Brasileira de Medicina Tropical, 31(2): 193-197.

Ishak, R., et al. (2003). Epidemiological aspects of retrovirus (HTLV) infection among Indian populations in the Amazon Region of Brazil. Cadernos de Saúde Pública, 19(4): 901-914.

Ishak, R., et al. (2020). The challenge of describing the epidemiology of HTLV in the Amazon region of Brazil. Retrovirology. 17: 4.

Johnson, L. \& Lewis, D. (2008). The effect of genital tract infections on HIV-1 shedding in the genital tract: A systematic review and meta-analysis. Sexually Transmitted Diseases, 35(11): 946-959.

Kajiyama, W., et al. (1986). Intrafamilial transmission of adult T cell leuckemia vírus. The Journal of Infetious Diseases, 154(5): 851-7.

Mayer, H., \& Venkatesh, K. (2011). Interactions of HIV, Other Sexually Transmitted Diseases, and Genital Tract Inflammation Facilitating Local Pathogen Transmission and Acquisition. American Journal of Reproductive Immunology. 65 (3): 308-16.

Mello, M. A. G., et al. (2014). HTLV-1 in pregnant women from the Southern Bahia, Brazil: a neglected condition despite the high prevalence. Virology Journal, 11:28.

Mome, R. K. B., et al. (2018). Effectiveness of female condom in preventing HIV and sexually transmitted infections: a systematic review protocol. BMJ Open, 8:e023055.

Moriuchi, H., et al. (2013). Mother-to-child transmission of human T-cell lymphotropic virus type 1. The Pediatric Infectious Disease Journal. 32 (2):175-77.

Mylonas, I., et al. (2010). HTLV infection and its implication in gynaecology and obstetrics. Archives of Gynecology and Obstetrics, 282:493-501.

Paiva, A., et al. (2017). High risk of heterosexual transmission of human T-cell lymphotropic virus type 1 infection in Brazil. Journal of Medical Virology. 89 (7):1287-94.

Paiva, A., \& Casseb, J. (2014). Sexual transmission of human T-cell lymphotropic virus type 1. Revista da Sociedade Brasileira de Medicina Tropical, $4 ; 47(3)$.

Pereira, F. M., et al. (2019). Evidence of New Endemic Clusters of Human T-Cell Leukemia Virus (HTLV) Infection in Bahia, Brazil. Frontiers in microbiology. 14. 
Research, Society and Development, v. 10, n. 4, e9410413867, 2021

(CC BY 4.0) | ISSN 2525-3409 | DOI: http://dx.doi.org/10.33448/rsd-v10i4.13867

Pique, C., \& Jones, K. S. (2012). Pathways of cell-cell transmission of HTLV-1. Frontiers of Microbiology 3:378.

Poiesz, B. J., et al. (1980). Detection and isolation of type C retrovirus particles from fresh and cultured lymphocytes of a patient with cutaneous T-cell lymphoma. Proceedings of the National Academy of Sciences of the United States of America, 77(12):7415-9.

Popovic, M., et al. (1982). The virus of Japanese adult T-cell leukaemia is a member of the human T-cell leukaemia virus group. Nature, 300(5887):63-66.

Romanelli, L. C. F., et al. (2010). Vírus linfotrópico de células t humanos tipo 1 (HTLV-1): quando suspeitar da infecção? Revista da Associcação Médica Brasileira, 56(3): 340-7.

Rosadas, C., et al. (2021). Protocolo Brasileiro para Infecções Sexualmente Transmissíveis 2020: infecção pelo vírus linfotrópico de células T humanas (HTLV). Epidemiologia e Saúde, 30: 171-194.

Roucoux, D. F., \& Murphy, E. L. (2004) The epidemiology and disease outcomes of human T-lymphotropic virus type II. AIDS Reviews,6(3):144-54.

Santos, E. L. D., et al. (2009). Caracterização molecular do HTLV-1/2 em doadores de sangue em Belém, Estado do Pará: primeira descrição do subtipo HTLV-2b na região Amazônica. Revista da Sociedade Brasileira de Medicina Tropical. 42:271-6.

Satake, M., et al. (2016). Incidence of human T-lymphotropic virus 1 infection in adolescent and adult blood donors in Japan: a nationwide retrospective cohort analysis. The Lancet. Infectious Diseases.16 (11):1246-54.

Schierhout, G., et al. (2019). Association between HTLV-1 infection and adverse health outcomes: a systematic review and meta-analysis of epidemiological studies. The Lancet Infectious Diseases. 20(1): 133-143.

Silva, I. C., et al. (2018). Moderada endemicidade da infecção pelo vírus linfotrópico-T humano na região metropolitana de Belém, Pará, Brasil. Revista Brasileira de Epidemiologia, 21, 1-14.

Souza, V. G., et al. (2012). High prevalence of HTLV-1 and 2 viruses in pregnant women in São Luis, State of Maranhão, Brazil. Revista da Sociedade Brasileira de Medicina Tropical, 45(2):159-162.

Tezuka, K., et al. (2020). HTLV-1 targets human placental trophoblasts in seropositive pregnant women. The journal of clinical investigation. 130 (11): 6171 86.

World Health Organization (2021). (6a ed.) Geneva: World Health Organization; 6th Edition of the WHO laboratory manual for the examination and processing of human semen.

Zunt, J. R., et al. (2002). Cervical shedding of human T cell lymphotropic virus type I is associated with cervicitis. The Journal of Infetious Diseases, 186:1669-1672. 